\title{
A Review on Artificial Aging Behaviors of Fiber Reinforced Polymer-matrix Composites
}

\author{
Jiangyan $\mathrm{MENG}^{\mathrm{a}}{ }^{*}$ and Yunying $\mathrm{WANG}^{\mathrm{b}}$ \\ Key laboratory of NDT (the Ministry of Education), Nanchang HangKong University, Nanchang, \\ China 330063 \\ aniat_meng@126.com \\ byywang4321@126.com
}

\begin{abstract}
As is known, factors in climate environment such as hygrothermal effect and UV may have a negative effect on the mechanical properties of fiber reinforced polymer-matrix composites, resulting in their strength and stiffness degraded. In this review, we summarize all the recent studies on the artificial climate aging, hygrothermal aging, and thermal-oxidation aging of fiber reinforced polymer-matrix composites, as well as their artificial accelerated aging and natural aging. In addition, studies on the aging property assessment and service-life prediction of fiber reinforced composites are introduced. Last but not least, the drawbacks and future trend of fiber reinforced composites aging are presented.
\end{abstract}

\section{Introduction}

Fibre reinforced polymer-matrix composite (FRPMC) offer a high strength, lightweight alternative to traditional methods of structural upgrade. Typically, FRPMC would consist of reinforcing fibre (e.g. glass, carbon, aramid, hybrid fibres) which is the hardest, strongest and stiffest component, embedded in a continuous matrix (e.g. polyester, vinyl ester, epoxy and urethane acrylate resins). The main functions of the matrix are to transmit externally applied loads to the reinforcement and to protect the latter from external mechanical and environmental damages [1-4].

In virtue of their high specific strength, high specific stiffness, excellent fatigue resistance and corrosion resistance, fiber reinforced polymer-matrix composites have been widely used in aerospace, maritime, mechanical and sports-related industries. In aerospace industry, composite materials have been utilized in fabrication of wings and fuselage of military aircrafts and large-scale application of fiber reinforced polymer-matrix composites will be observed in civilian airliners in the near future. Nevertheless, during the machining, storage and application, composite materials are sensitive to climate environment as oxygen, moisture and sunlight may have an effect on their aging process. As a result, investigations on their fatigue resistance in environment conditions are essential.

\footnotetext{
* Corresponding author:niat_meng@126.com
} 
To date, fiber reinforced polymer-matrix composites available include carbon fiber composite, glass fiber composite, organic fiber composite and ceramic fiber composites[5]. Polymer aging is resulted from both internal and external factors[6]. The external factor refers to the application environment, in which light(UV), heat(high teperature), moisture and oxygen can have a significant effect, while the internal factors include the composition, chain structure and changes in aggregation structure. In most cases, polymer aging is a result of interaction between internal and external factors.

\section{Artificial Climate Aging}

Artificial climate aging is defined as the aging processes that are accelerated by simulation of outdoor climate in the lab. For instance, natural light is replaced by xenon arc lamp as the UV light can cause partial degradation of macro molecules in the resin matrix, thus aging and failure of polymer[7].

Brian Burks, Maciej Kumosa [8] reported the effect of thermal exposure in an atmospheric environment for up to 1 year on the flexural performance, under both static and fatigue loading, of a glass fiber/carbon fiber hybrid polymer matrix composite material was evaluated. It was found that exposure to a temperature near, but below, the glass transition temperature resulted in diminished flexure strength as well as reduced fatigue performance. The magnitude of property reduction was, in general, proportional to the amount of aging time, and was found to be dictated by the dominant aging mechanism. Scanning electron microscopy revealed that the modest reduction in mechanical properties at intermediate aging times was predominantly attributed to thermal oxidation, while for longer aging times thermal aging (dimensional relaxation) was the primary cause for the substantial reduction. Dimensional relaxation of the composite was measured at several isothermal aging temperatures, from which, the activation energy of the aging process was determined. Their work provides insight into the evolution of mechanical properties as a function of aging time in an atmospheric environment for a hybrid polymer matrix composite.

Zhang. J. M, et al [9] presented a simulation of the environment for aircrafts by 'xenon arc light-humidification' cyclic test. According to their results, as the aging continues, degradation was observed at the interface of the matrix and fibers, resulting in $34.8 \%$ decrease in lateral tensile strength and $18.2 \%$ decrease in inter-laminar shear strength in the worst case, as shown in Table 1 below. The xenon light can lead to reaction of epoxy resin on the surface, which resulted in breakage/cross-linking of some molecules. For this reason, cracks and exposed fibers were observed. 
Table 1 The Mechanical Properties Of Composites Before And After Aging[9]

\begin{tabular}{|c|c|c|c|c|c|c|c|c|}
\hline & $\begin{array}{l}\text { Un } \\
\text { age } \\
\text { d }\end{array}$ & $\begin{array}{c}\text { Cyc } \\
\text { le } \\
336 \\
\text { h }\end{array}$ & $\begin{array}{c}\text { Cyc } \\
\text { le } \\
672 \\
\text { h }\end{array}$ & $\begin{array}{c}\text { Cyc } \\
\text { le } \\
100 \\
8 \mathrm{~h}\end{array}$ & $\begin{array}{l}\text { Humidify } \\
\text { ing } 224 \mathrm{~h}\end{array}$ & $\begin{array}{l}\text { Irradiatio } \\
\text { n } 224 \text { h, } \\
\text { Humidify } \\
\text { ing } 112 \text { h }\end{array}$ & $\begin{array}{l}\text { Irradiatio } \\
\text { n } 448 \text { h, } \\
\text { Humidify } \\
\text { ing } 224 \text { h }\end{array}$ & $\begin{array}{c}\text { Irradiati } \\
\text { on } 448 \\
\mathrm{~h}\end{array}$ \\
\hline $\begin{array}{l}\text { Shear } \\
\text { streng } \\
\text { th } \\
(\mathrm{MPa})\end{array}$ & $\begin{array}{c}8.3 \\
1\end{array}$ & 7.47 & 7.24 & 7.45 & 6.80 & 7.02 & 6.84 & 7.34 \\
\hline $\begin{array}{l}\text { Chan } \\
\text { ge } \\
\text { perce } \\
\text { nt }(\%)\end{array}$ & & $\begin{array}{c}-10 . \\
1\end{array}$ & $\begin{array}{c}-12 . \\
9\end{array}$ & $\begin{array}{c}-10 . \\
3\end{array}$ & -18.2 & -15.5 & -17.7 & -11.7 \\
\hline $\begin{array}{c}\text { Tensil } \\
\mathrm{e} \\
\text { streng } \\
\text { th } \\
(\mathrm{MPa})\end{array}$ & $\begin{array}{c}41 . \\
1\end{array}$ & 45.4 & 34.4 & 26.8 & 37.2 & 37.32 & 30.98 & 32.02 \\
\hline $\begin{array}{l}\text { Chan } \\
\text { ge } \\
\text { perce } \\
\text { nt }(\%)\end{array}$ & & 10.4 & $\begin{array}{c}-16 . \\
3\end{array}$ & $\begin{array}{c}-34 . \\
8\end{array}$ & -9.5 & -9.72 & -24.6 & -22.09 \\
\hline
\end{tabular}

X.,Lü,et al presented a simulation of the marine environment in South China Sea [10]. In this experiment, carbon fiber reinforced polymer-matrix composites were immersed in $3.5 \%$ (mass fraction) $\mathrm{NaCl}$ solution and deionized water respectively and the effects of these two conditions on the mechanical properties of the composites were investigated. The results revealed that incubation at both $30^{\circ} \mathrm{C}$ and $80^{\circ} \mathrm{C}$ led to decreases in mechanical properties of composites, while incubation at high temperature gave a larger decrease. For example, $27 \%$ decrease in static mechanical properties was observed for composites after incubation in deionized water at $80^{\circ} \mathrm{C}$ for 30 days. Similarly, Ma Tingting, et al[11] presented a study on the effect of water on the mechanical properties of T300/NY9200 composite material and its mechanism. It is shown that water absorption of carbon fibers was indeed lower, the degradation of fiber/matrix interface due to diffusion of water molecules into the matrix is believed to be the key reason for degraded shear strength of the composite.

L.Monney, C. Dubois, et alpresented an investigation on the photo-degradation of composite with epoxy resin as the matrix and methyl tetrahydrophthalic anhydride as the curing agents by infrared spectrophotometry and $\mathrm{XRD}[12]$. The results revealed that a thin oxidation layer was formed as a result of photo-oxidation on the surface, and the growth of 
oxidation layer and shrinking of organic matrix continued at a constant rate. Meanwhile, stress testing was conducted to samples after UV accelerated aging 1000 hours and 2-year natural aging process. It has been found that no obvious degradation of mechanical properties was observed for the samples, indicating that the photolysis was on the surface.

Zhan Maosheng, et al presented an investigation on the aging behavior of unidirectional glass fiber reinforced epoxy resin composite in moisture absorption/desorption cyclic test in hygrothermal conditions or in the presence of acid rain[13]. In this experiment, water solution with $\mathrm{pH}$ of 4.7 was used to imitate acid rain. According to their results, moisture absorption in both cases followed Fick's Law of diffusion. As the absorption/desorption cyclic test continues, mechanical properties of the material degraded and its glass-transition temperature (Tg) decreased. In the presence of acid rain, larger degradation of mechanical properties and decrease of $\mathrm{Tg}$, accompanied by severe interface debonding, were observed, although the debonding can be partially recovered by second moisture desorption.

Liu J H, et al[14] presented an investigation on the change in mechanical properties of glass fiber reinforced polymer (GFRP) in marine environment. Here, neutral salt spray was used for simulation of the marine environment. At the initial stage, the weight of GFRP increased due to moisture absorption, resulting in slight increase in compressive strength and inter-laminar shear strength in virtue of plastification-induced toughening. Nevertheless, the mechanical strength degraded as the salt spray aging continued in the overall process, while the degradation was fastest at the initial stage. Additionally, an exponential decrease was observed for the tensile strength of the sample.

Zhu Chunya, et al presented an investigation on the xenon-arc lamp accelerated aging behavior of glass reinforced $191 \#$ unsaturated polyester in terms of change in the mechanical properties, surface morphology and gloss reduction. Owing to post-curing and physical aging, mechanical properties of the sample were enhanced and then degraded, while the surface gloss reduction increased and obvious cracks were observed. In addition, the retention ratio of flexural strength and shear strength was $92 \%$ and $53 \%$ respectively after aging for $1800 \mathrm{~h}$, indicating that the resistance of GRP to aging accelerated by xenon arc lamp is poor[15].

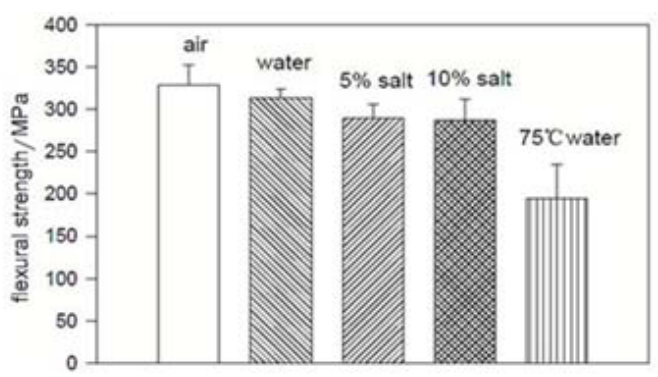

Figure 1. Flexural strength of composites before and after aging [16]

K.Liao, et al [16] presented an investigation on the aging behavior of pultruded GFRP in water at different temperatures and salt solutions with different concentrations. According to their report, the flexural strength of sample decreased as a result of aging in both water and salt solutions, as shown in Figure 1 below. Meanwhile, severe degradation was observed in the fracture mirror area of glass fiber and resin matrix on some fibers in the failure plane decreased significantly, shown in Figure 2. 

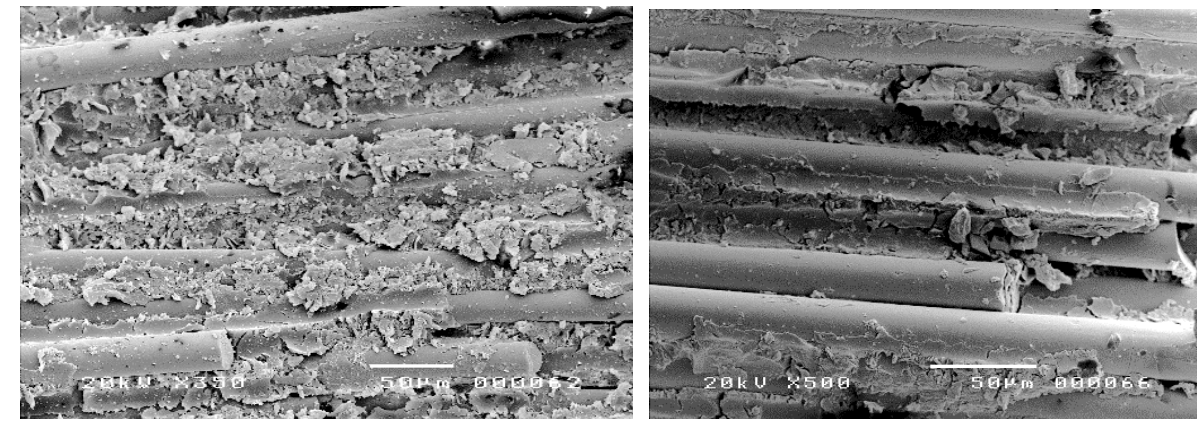

Figure 2. Morphologies of the composites before and after aging [16]

\section{Thermal-oxidation Aging}

Besides UV, heat and oxygen are also key factors in the environment in the aging process of polymers. Thermal- oxidation accelerated aging refers to the process where static/dynamic mechanical properties of samples with long-term exposure to thermal aging furnace/oven are monitored to investigate the effect of the exposure to structures and properties of composites, thus the mechanisms of thermal-oxidation aging. Thermal-oxidation of a polymer matrix composite (PMC) introduces damage at the fiber/matrix interfaces and causes formation of micro-cracks, and it in turn degrades the structural property and alters its failure mechanisms. The service life of PMC is significantly affected by degradation for high temperature applications. The degradation is often investigated under accelerated conditions at elevated temperatures. Carbon fiber BMI composite is one of the high temperature composites often used in aircraft, especially in the primary and secondary structures, and is investigated in the reference[17].

M., Akay, et al presented an investigation on the effect of fiber type and exposure to high-temperature environment $\left(210^{\circ} \mathrm{C}, 230^{\circ} \mathrm{C}\right.$ and $\left.250^{\circ} \mathrm{C}\right)$ on the inter-laminar shear strength and impact resistance of carbon fiber/ bismaleimide [18]. As shown in Figure 3 below, the inter-laminar shear strength and maximum peak strength per ligament area decreased with increasing aging temperature. Additionally, the failure of impacted sample was delamination failure after aging instead of brittle failure before aging. It can be concluded that aging took place in resin matrix, fiber and the interface between them.

Dinh Quy Vu,et al [19] focuses on the experimental characterization of thermo-oxidation in carbon-fiber-reinforced polymers exposed to 'high' temperatures (up to $150^{\circ} \mathrm{C}$ ) and 'high' oxygen pressures (up to 5 bars), at the microscopic scale. Unidirectional IM7/977-2 composite specimens were aged at $150^{\circ} \mathrm{C}$ under atmospheric air and under oxygen pressure (1.7 bars and 5 bars) periodic tests were carried out to characterize degradation phenomena after different aging times. The thermo-oxidation-induced resin shrinkage and fiber/matrix debonding were measured on the sample surface by confocal interferometric microscopy and scanning electron microscopy. The results show that thermo-oxidation induced degradation strongly depends on aging time, distance between fibers and partial oxygen pressure.

Zhang Yan-ping, et al[20] reported an investigation on the thermal-oxidation aging behavior of carbon fiber/epoxy resin at different temperatures and several conclusions have been drawn. Firstly, material weight loss increased exponentially with aging duration, and higher temperature led to larger weight loss with the same aging duration. Secondly, the flexural strength retention ratio of samples aged at $100^{\circ} \mathrm{C}$ and $150^{\circ} \mathrm{C}$ increased in the early 
stage till a maximum value was reached, and decreased linearly after that. Thirdly, aging at temperatures under $150^{\circ} \mathrm{C}$ was mainly physical aging, while both physical and chemical aging were observed if $\mathrm{T}>150^{\circ} \mathrm{C}$.

$\mathrm{Li}$ X J, et alreported a study on the thermal-oxidative aging behavior of T300/5405 and T300/HD03 carbon reinforced composite[21]. In this experiment, the composites were aged at $60^{\circ} \mathrm{C}, 80^{\circ} \mathrm{C}, 100^{\circ} \mathrm{C}, 150^{\circ} \mathrm{C}$ and $180^{\circ} \mathrm{C}$ respectively for $5500 \mathrm{~h}$ and changes in properties such as weight loss, mechanical properties and Tg were monitored in the whole process. It is shown as follows. 1) T300/5405 showed a less weight loss as compared to T300/HD03, as shown in Figure 3. 2) The compressive strength and flexural strength of T300/5405 at room temperature was sensitive to the aging process (Table 2), while compressive modulus, shear modulus and high-temperature flexural strength of T300/HD03. 3) Phenomena such as moisture desorption, volatilization of residual low molecular components, post-curing, thermal degradation and physical aging is closely related to the temperature.

Lei Wen, et al [22], and M.L.Guo,et al [23] conducted an investigation on the effect of coupling agent on the mechanical properties of hemp fiber/unsaturated polyester resin composites. In this experiment, $600 \mathrm{~h}$ thermal -oxidation aging was applied to the samples. It has been reported that treatment by coupling agent KH570 resulted in best improvement of sample's mechanical properties. No significant shift in the IR absorption peak was observed for the KH570 treated sample, while characterization by SEM showed that the treated fibers were distributed uniformly in the polymer matrix and the fiber/matrix interfacial adhesion was good.

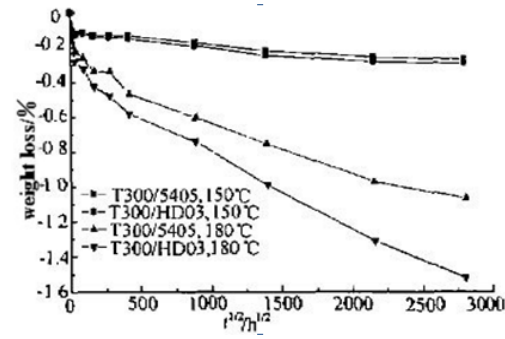

Figure 3. Weight Loss-time curve when T300/5405 and T300/HD03 thermal oxidative aging at $150^{\circ} \mathrm{C}$ and $180^{\circ} \mathrm{C}[21]$

Table 2 Strength Retention Ratio For T300/5405 And T300/Hd03 Under Thermal-Oxidative Aging Below $100^{\circ} \mathrm{C}$ For 5500 H[21]

\begin{tabular}{|c|c|c|c|c|c|c|c|}
\hline \multirow{2}{*}{\multicolumn{2}{|c|}{$\frac{\text { Composites }}{\text { Temp of aging }\left({ }^{\circ} \mathrm{C}\right)}$}} & \multicolumn{3}{|c|}{ T300/5405 } & \multicolumn{3}{|c|}{ T300/HD03 } \\
\hline & & \multirow{3}{*}{$\begin{array}{c}60 \\
1.053 \\
0.836\end{array}$} & \multirow{3}{*}{$\begin{array}{c}80 \\
1.064 \\
0.88\end{array}$} & \multirow{3}{*}{$\begin{array}{c}100 \\
1.074 \\
0.822\end{array}$} & \multirow{3}{*}{$\begin{array}{c}60 \\
0.950 \\
0.699\end{array}$} & \multirow{3}{*}{$\begin{array}{c}80 \\
0.921 \\
0.771\end{array}$} & \multirow{3}{*}{$\begin{array}{c}100 \\
1.113 \\
0.747\end{array}$} \\
\hline Flexural & RT & & & & & & \\
\hline strength*(MPa) & $150^{\circ} \mathrm{C}$ & & & & & & \\
\hline \multicolumn{2}{|c|}{ Flexural modulus (MPa) } & 1.058 & 1.051 & 1.052 & 0.94 & 0.938 & 1.031 \\
\hline Shear strength* & RT & 1.122 & 1.094 & 1.013 & 1.066 & 0.986 & 1.073 \\
\hline (MPa) & $150^{\circ} \mathrm{C}$ & 1.009 & 1.012 & 0.923 & 0.871 & 0.859 & 0.881 \\
\hline \multicolumn{2}{|c|}{ Compressive strength(MPa) } & 0.894 & 0.904 & 0.871 & 0.993 & 1.047 & 1.122 \\
\hline \multicolumn{2}{|c|}{ Modulus of compression (GPa) } & 0.802 & 0.792 & 0.802 & 0.701 & 0.76 & 0.726 \\
\hline
\end{tabular}

* = testing temperature; $\mathrm{RT}=$ room temperature 

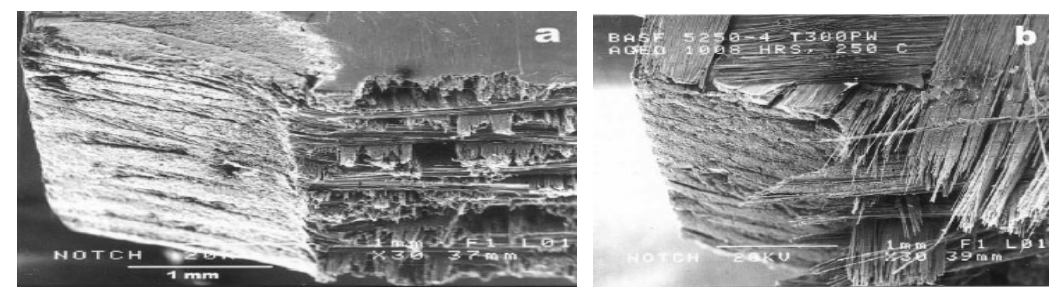

Figure 4. Morphologies of the rupture surface of composites before and after aging at $250^{\circ} \mathrm{C}[22]$

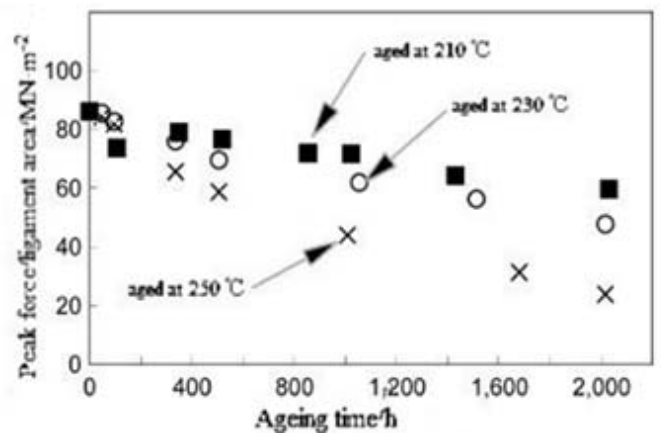

Figure 5. Effect of aging time on maximum peak strength per ligament area for T300/5250 composite ${ }^{[23]}$

\section{Artificial Hygrothermal Aging}

The effect of hygrothermal environment on the composite materials can be divided into three aspects. Firstly, the hygrothermal environment may lead to damages to the resin matrix, reinforcing fibers and the interface between them. Secondly, temperature variation can be a source of thermal stress damage. Thirdly, moisture absorption may result in plastification in matrix and damage to the crystalline structure, thus crack growth [24-26].

Sakai.M., et al [27] reported a novel tensile test for the study of interfacial failure in unidirectional carbon fiber reinforced carbon matrix composite. With this method, the processes of interfacial debonding and subsequent pull-out of a fiber bundle from the surrounding composite medium can be observed. Also, it was reported that the critical stress at the onset of delamination cracking is related to the fracture energy as shown in the Eq. (1) below. 


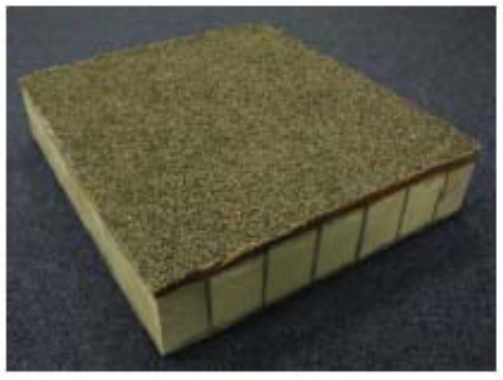

Figure 6. Composite deck of the sandwich ${ }^{[24]}$

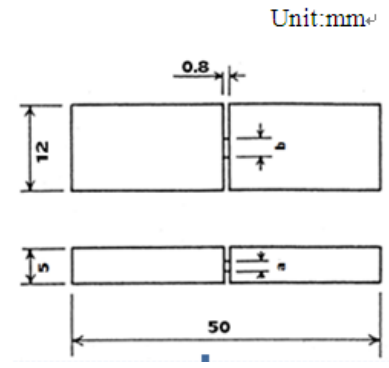

Figure 7. Geometry and dimensions of tensile test specimen ${ }^{[27]}$

$$
\sigma_{d}=\sqrt{\frac{4 E G_{I I c}}{a b /(a+b)}}
$$

Note: $a$ and $b$ are the widths of the ligament, $E$ is the Young's modulus of the composite along the orientation of reinforcing fibers and $G_{\text {IIc }}$ is the fracture energy

H.S.Choi., et al presented an study of hygroscopic effects on epoxy/carbon fiber composite laminates [28]. It was found that the specimen thickness had little effect on the through-the-thickness water absorption behavior of composite laminates, but other parameters such as matrix volume ratio $(\mathrm{Vm})$, void volume ratio $(\mathrm{Vv})$ and internal stress affected the moisture absorption rate and equilibrium water uptake in different ways and intensities. In addition, the glass transition temperature ( $\mathrm{Tg}$ ) of composite laminates was strongly affected and linearly decreased by the quantity of equilibrium water uptake.

Wang Xiaojie, et alreported an investigation on hygrothermal aging behaviors of T700 fiber/epoxy and F-12 fiber/epoxy composites at $85^{\circ} \mathrm{C}$ and $95 \%$ relative humidity[29]. The results revealed that the mass losses of both composites were maximized at $500 \mathrm{~h}$. After aging for $2000 \mathrm{~h}$, T700 sample did not show water desorption and its mass retention ratio was $70 \%$, while water desorption and volatilization of low molecular components were still observed in F-12 sample and its mass retention ratio was merely $50 \%$.

Zhou $\mathrm{T}$ Y, et al investigated the water absorption and glass transition temperature (Tg) of Vinyl Ester Resin (VE) castings and its carbon fiber composite in distilled water at $65^{\circ} \mathrm{C}$ and $95^{\circ} \mathrm{C}$ respectively[30]. According to the results, water absorption of the sample can be categorized into matrix absorption and interface absorption. Both flexural strength of the composite and flexural modulus of the casting were decreased with increasing water absorption ratio, while flexural modulus change was relatively larger. On the other hand, both samples showed decreasing Tg with aging in the early stage, but kept constant as a result of water absorption saturation. However, the internal friction peaks of these two samples showed opposite trends.

Chen Weiming, et al reported an investigation on the hydrothermal aging behaviors of carbon fiber/epoxy resin in distilled water at $65^{\circ} \mathrm{C}$ and $95^{\circ} \mathrm{C}$ respectively [31]. It was reported the change in apparent activation energy of glass transition $(\Delta \mathrm{Ea})$ before and after aging was varied for different resin matrix composites, and $\Delta \mathrm{Ea}$ increased with increasing 
aging temperature. Also, it was proved that $\Delta \mathrm{Ea}$ decreased with decreasing equilibrium water uptake in hygrothermal environment, while increased with decreasing mechanical properties retention ratio of the composite after hydrothermal aging.

Guo Mei-li, et al reported an investigation on the hygrothermal aging mechanisms of $\mathrm{T} 300 / 5405$ and T300/NY9200 composite materials in water at $80^{\circ} \mathrm{C}$. It was revealed that the aging the samples are mainly caused by plasticizing and swelling effect of water on the matrix and the micro-cracking caused by expansion mismatch (between resin and fibers) induced internal stress[32].

Xiao Yinghong, et al[33] reported a study of hygrothermal ageing behaviors of glass fiber reinforced thermoplastic polyester composite. It was revealed that mechanical properties of the sample degraded significantly, which was caused by interfacial debonding as a result of water diffusion into the material.

T.I.Tsai., et al[34] reported an investigation on the absorption and diffusion of water in a carbon fiber/glass fiber hybrid composite. The results revealed that weight-change profiles for the composites fitted the theoretical Fickian diffusion curve during the initial immersion time, but diverged substantially as time progressed. The shear properties and the glass transition temperature ( $\mathrm{Tg}$ ) decreased with increasing water uptake. Microscopic inspection of water-soaked samples showed no cracking when the absorption was less than saturation. The thermal and mechanical properties were mostly retained (after drying), provided the moisture absorption did not exceed the saturation point.

M.P.Foulc., et al presented an investigation on the hygrothermal ageing behaviors of glass fiber reinforced polyethylene terephthalate(PET) composites[35]. The samples were aged by immersion in deionized water at $120^{\circ} \mathrm{C}$. It was revealed that plasticization of the PET matrix was observed at early ageing stage and random chain scission is believed to be the main degradation mechanism.

M.D.H.Beg., et al[36] presented an investigation on the hygrothermal ageing behavior of composites based on radiata pine (Pinus Radiata) wood fiber with a polypropylene matrix. It was found that the diffusion coefficient of composites decreased with increasing immersion duration till saturation at 150 days. After hygrothermal ageing, tensile strength, Young's modulus and hardness of the sample were found to decrease, but impact strength and failure strain increased. Also, the thermal stability of both PP and the composite was found to decrease after hygrothermal ageing, although the degradation can be relieved by coupling agent. Plasticization of matrix and degradation of fiber/matrix interface bonding were considered as the main reasons for changes in physical and mechanical properties of the composites.

\section{Lifetime Predict of the Composites}

Mohammad H. Haque and Priyank Upadhyaya,et al [37] examines the changes in weight loss and flexural properties along with the changes in microstructures of unidirectional carbon fiber reinforced bismaleimide with [016] and [9016] specimens, after exposure to $260^{\circ} \mathrm{C}$ for $3000 \mathrm{~h}$ in air. The percentage of fiber end area exposed to air in a specimen end section significantly influences the extent of these changes. The [9016] specimens have an order of magnitude higher fiber open ends than the [016] specimens, and their weight loss rate and loss in flexural modulus and strength are significantly higher than that of the [016] specimens. In three point bending, interlaminar shear leads to delamination preceding the final failure in compressive mode. A viscoelastic cohesive layer model has been implemented to simulate interlaminar delamination. Viscoelastic regularization of the constitutive equations of the cohesive layer used in this model not only mitigates numerical instability, but also predicts load-deflection behavior beyond peak failure load. The model 
is in a good agreement with experimental results and has been able to simulate the delamination failure successfully.

In the paper of Priyank Upadhyaya and Samit Roy, a novel numerical-experimental methodology is outlined to determine cohesive stress and damage evolution parameters for pristine as well as isothermally aged (in air) polymer matrix composites[38]. A rate-dependent viscoelastic cohesive layer model was implemented in an in-house test-bed finite element analysis code to simulate the delamination initiation and propagation in unidirectional polymer composites before and after aging. To determine the model parameters, double cantilever beam experiments were conducted on both pristine and isothermally aged IM-7/bismaleimide (BMI) composite specimens. The J-integral approach was adapted to extract cohesive stresses near the crack tip. A principal-stretch dependent internal damage state variable defines the damage in the cohesive layer. Within the cohesive layer, pristine and cohesive stresses were compared to estimate the damage parameters. Once the damage parameters had been characterized, the test-bed FEA code employed a micromechanics based viscoelastic cohesive layer model to simulate interlaminar delamination. The present cohesivelayer based FEA model was able to accurately predict not only the macro-level load-displacement curve, but also the micro-level crack growth history in IM-7/BMI laminate before and after thermal aging.

R.P.Snaha and W.C.Scott presented an modeling and evaluation of combined hygrothermal conditions on the strength and life of a graphite/epoxy woven composite material system [39]. In this experiment, hygrothermal cycling of room temperature, $120^{\circ} \mathrm{C}$ and $30^{\circ} \mathrm{C} / 85 \%$ relative humidity was applied to the sample. By prediction of residual strength, the author obtained information about quasi-static mechanical properties, fatigue damage and fatigue life of the composite. It was claimed that fatigue life and residual strength of the woven graphite/epoxy composite material studied are minimally affected by temperature, moisture and stress level applied. The damage progression during fatigue occurred in the following order: transverse micro-cracking and delamination around the fiber bundle undulation regions, growth of longitudinal and transverse cracks across the entire height of the transverse fiber bundle, and cross-ply-like growth of edge and interply delamination. The rate at which damage progression occurred generally depended on the maximum fatigue stress amplitude and environment in that: 1) damage accumulation was found to be greater with decreasing fatigue stress levels. 2) fiber/matrix debonding and delamination were found to be greater for the elevated-temperature and moisture-saturated specimens than for room-temperature specimens. 3) hygrothermal cycling during fatigue was found to result in greater crack density during fatigue than did any of the other three conditions. These results suggest that the fatigue life of this material may be more adversely affected by environment for off-axis loading situations than was captured by the fiber-direction loading case considered in this study (Figure 8).
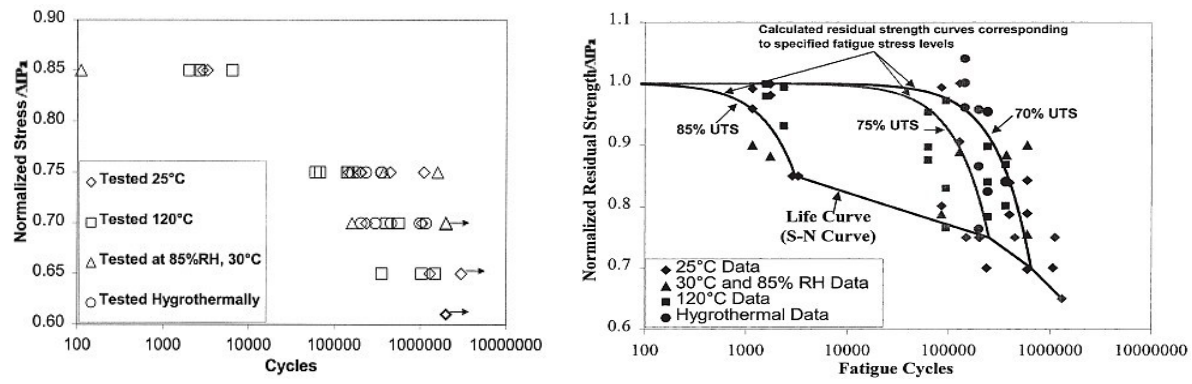

Figure 8. The result of fatigue life ${ }^{[39]}$ 
Initiation of fatigue damage for a hybrid polymer matrix composite material was studied via 3-Dimensional viscoelastic representative volume element modeling in order to gain further understanding. It was found that carbon fiber reinforced composites perform better in fatigue loading, in comparison to glass fiber reinforced composites, due to the fact that the state of stress within the matrix material was considerably lower for carbon fiber reinforced composites eliminating (or at least prolonging) fatigue damage initiation. The effect of polymer aging was also evaluated through thermal aging of neat resin specimens. Short-term viscoelastic material properties of unaged and aged neat resin specimens were measured using Dynamic Mechanical Analysis. With increasing aging time a corresponding increase in storage modulus was found. Increases in the storage modulus of the epoxy matrix subsequently resulted in a higher state of predicted stress within the matrix material from representative volume element analyses. Various parameters common to unidirectional composites were numerically investigated and found to have varying levels of impact on the prediction of the initiation of fatigue damage.

\section{Conclusion}

The climate-resistance (aging mechanisms) of polymer-matrix composites is determined by the resin matrix and adsorption of fiber on the interface. In most cases, composite materials show good weather-resistance. More specifically, their resistance to thermal oxidative aging is better as compared to the resistance to UV aging and hygrothermal aging.

Currently, investigations are focusing on the change in the macroscopic characteristics of fiber reinforced polymer-matrix composites, such as appearance and mechanical properties, while intensive and systematic study of changes in the microscopic structures and the aging mechanisms has not been done. Moreover, the simulation of environment in current studies is usually simplified to moisture, thermal or hygrothermal conditions, while other factors such as light, oxygen and biological factors have not been systematically investigated.

As a result, here are some suggestions for investigation on aging behaviors of composite materials.

The standards for accelerated aging experiments of polymer-matrix composites should be established. Intensive and systematic investigations on the aging mechanisms of polymer-matrix composites should be conducted.

A database where all relevant studies are included to avoid redundant experiments should be established.Strengthening the relevance between accelerated aging and natural aging by involving mathematical modeling and computer simulation, thus predicting working life of materials.

\section{Acknowledgement}

This work was supported by the Aeronautics Science Foundation (20120956005).

\section{References}

1. Matthews F L, Rawlings R D. Composite materials: engineering and science[M]. London: Chapman and Hall, 1994.

2. Karbhari V M. Durability of composites for civil structural applications[M]. 1st ed. New York: CRC Press, 2007.

3. Won J P, Park C G. Effect of environmental exposure on the mechanical and bonding properties of hybrid FRP reinforcing bars for concrete structures[J]. Journal of 
Composites Material, 2006;40:1063-76.

4. ACI 440.1R-06. Guide for the design and construction of structural concrete reinforced with FRP bars, 2006.

5. D. Wo. Encyclopedia of Composites [M]. Chemical industry press, 2000, 11-12.

6. S. Zhong, Q. Xu, G. Wang. Juhewu Jiangjie Yu Wendinghua [M]. Chemical industry press, 2002, 2-8.

7. Brian Burks, Maciej Kumosa. The effects of atmospheric aging on a hybrid polymer matrix composite[J]. Composites Science and Technology,2012,72:1803-1811.

8. J.Y. Meng, Y. Y.Wang, Q. Zhao. Accelerated aging mechanism of unsaturated polyester[J]. Failure Analysis and Prevention, 2009, 4(2):65-70.

9. J. Zhang, Y. Chen, Accelerated aging behavior of aircraft structural composite[J]. Science Technology and Engineering, 2008, 8(23):6338-6342.

10. X. Lü, Q. Zhang, Z. Ma. Study of hygrothermal aging effect on mechanical properties of carbon fiber/epoxy resin composites [J]. Journal of Materials Engineering, 2005(11):50-57.

11. T. Ma, S. Bai, R. Luo. Mechanical properties of carbon fiber reinforced epoxy resin composites after aging in water and its mechanism [C]. Journal of 14th National Conference on Composite Materials, 2006, 417-422.

12. L. Monney, C. Dubois, D. Perreux. Mechanical behavior of an epoxy-glass composite under photo-oxidation [J]. Polymer Degradation and Stability, 1999, 63:219-224.

13. M. Zhan, D. Liu. Acid rain cycling aging properties and mechanism of unidirectional glass fiber reinforced epoxy resin composites [J]. Fiber Reinforced Plastics/Composites, 2007(3):28-32.

14. J. Liu, L. Zhao, S. Li. Effect of salt spray on mechanical properties of glass fiber reinforced polymer composites [J]. Acta Materiae Compositae Sinica, 2007, 24(3):18-22.

15. C. Zhu, Q.Zhao, J. Meng. 191\# Unsaturated polyester/GFRP artificial accelerated aging research [J]. Failure Analysis and Prevention, 2008, 3(3):12-16.

16. K. Liao, C. R. Schultheisz, D. L. Hunston. Effects of environmental aging on the properties of pultruded GFRP [J]. Composites: Part B, 1999, 30:485-493.

17. L. Yuan, B. Gu, Y. Chen. Study on thermal-oxidative aging damage of fiber reinforced rubber sealing material part I - the model of thermal-oxidative aging damage [J]. Lubrication Engineering, 2006(1):78-80.

18. M. Akay, G. Spratt, B. Meenan. The effects of long-term exposure to high temperatures on the ILSS and impact performance of carbon fiber reinforced bismaleimide [J]. Composites Science and Technology, 2003, 63:1053-1059.

19. Q.V. Dinh, G. Marco, C.L.F. Marie. Experimental characterization of thermo-oxidation-induced shrinkage and damage in polymer-matrix composites[J]. Composites, Part A,2012,43: 577-586.

20. Y. Zhang, J. Xiong, Y. Zuo, Thermal-oxidative aging mechanisms of carbon fiber/epoxy resin composites[J]. Journal of Beijing University of Chemical Technology, 2007, 34(5): 523-527.

21. X. Li, F. Xu, X. Chen. Study of thermal-oxidative aging of advanced polymer-matrix composites[J]. Journal of Materials Engineering, 1999(12):2-8.

22. W. Lei, T. Yang. Effect of thermal-oxidative aging on properties of hemp fiber/unsaturated polyester resin composites[J]. Fiber Reinforced Plastics/Composites,2009(5):36-40.

23. M. Guo, Y. Zhao, F. Xu, Study of aging of advanced polymer-matrix composites I. thermo-oxidative aging[J]. Journal of Materials Engineering, 2000(21): 62-65.

24. K. Apisit, R.Vichai, H. Hiroyuki, at al. Anti-fungal performance and mechanicalemorphological propertiesof PVC and wood/PVC composites under 
UV-weathering aging and soil-burial exposure[J]. International Biodeterioration and Biodegradation,2014,91:128-137.

25. Guo C. Effects of hygrothermal aging on structures and properties of cyanate/epoxy novolac blends [J]. Acta Materiae Compositae Sinica, 2002, (3):6-9.

26. J.g Xu, K. Henk, B. Frans, et al. Effects of hygrothermal aging on glass-fibre reinforced polymer laminates and adhesive of FRP composite bridge: Moisture diffusion characteristics[J]. Composites: Part A,2014,57:49-58.

27. M. Sakai, R. Matsuyama, T. Miyajima. The pull-out and failure of a fiber bundle in a carbon fiber reinforced carbon matrix composite [J]. Carbon, 2000, (38):2123-2131.

28. H.S.Choi, K. J. Ahn, J.D.Nam. Hygroscopic aspects of epoxy/carbon fiber composite laminates in aircraft environments [J]. Composites: part A, 2001, 32:709-720.

29. X. Wang, G. Liang, W. Zhang. Effects of hydrothermal aging on properties of high-performance composites [J]. Journal of Solid Rocket Technology, 2009, 29(3):301-304.

30. T. Zhou, Y. Yu, W. Chen. Hygrothermal aging behavior of vinyl ester resin and its CF composite [J]. Polymer Materials Science \& Engineering, 2006, 22(5): 166-169.

31. W. Chen, C. Wang, T. Zhou. Study on hydrothermal properties of carbon fiber composites with multi-frequency dynamic mechanical thermal analysis [J]. Journal of Materials Engineering, 2006(27):355-365.

32. M. Guo, Y. Zhao. Study on hygrothermal ageing mechanisms of aerospace structural composites [J]. Aerospace Materials \& Technology, 2002(4): 51-54.

33. Y. Xiao, X. Wang, L. Lu. Study on the hygrothermal ageing of glass fiber reinforced thermoplastic polyester composite [J]. Engineering Plastics Application, 2001, 29(9):35-37.

34. Y. Tsai, E. Bosze, E. Barjasteh. Influence of hygrothermal environment on thermal and mechanical properties of carbon fiber/fiberglass hybrid composites [J]. Composites Science and Technology, 2009, (69):432-437.

35. M. Foulc, A. Bergeret, L. Ferry, et al. Study of hygrothermal ageing of glass fiber reinforced PET composites [J]. Polymer Degradation and Stability, 2005, (89):461-470.

36. M. Beg, K. Pickering. Reprocessing of wood fibre reinforced polypropylene composites Part II: hygrothermal ageing and its effects [J]. Composites: Part A, 2008, (39):1565-1571.

37. H. Mohammad, U. Priyank, R. Samit., et al. The changes in flexural properties and microstructures of carbon fiber bismaleimide composite after exposure to a high temperature[J]. Composite Structures,2014,108:57-64.

38. U. Priyank, R. Samit, H. Haque. Mohammad.,et al. A novel numerical-experimental approach for predicting delamination in high temperature polymer matrix composites[J] . Composite Structures, 2013,104: 118-124.

39. S. Patel, S. Case. Durability of a graphite/epoxy woven composite under combined hygrothermal conditions[J]. International Journal of Fatigue, 2000(22):809-820.

40. Brian Burks, James Middleton, Maciej Kumosa. Micromechanics modeling of fatigue failure mechanisms in a hybrid polymer matrix composite [J]. Composites Science and Technology,2012,72:1863-1869. 